\title{
Urban Growth and Circular Flow in a SAM-framework: The Case of The Netherlands
}

\author{
S. I. COHEN \\ Faculty of Economic Sciences, Erasmus University, Postbox 1738, 3000 DR , Rotterdam, The Netherlands
}

\begin{abstract}
This paper follows an approach different from those commonly taken in assessing trends and impact of the economy on urbanization. A social accounting matrix (SAM) for The Netherlands, which distinguishes between six levels of urbanization, is inverted to give multiplier effects of institutional transfers and sectoral injections on urbanization levels. Multipliers of the SAM are analyzed for two different periods. Changes in urban performance are decomposed into changes in multipliers and in exogenous effects which are often controlled by policy makers. Copyright $\mathbb{C} 1996$ Elsevier Science Ltd.
\end{abstract}

\section{INTRODUCTION}

In seeking a simplified way of looking at trends and changes in urban development we usually describe urban dynamics to consist of a four stage cyclus: (1) industrialization occurs with major growth for the manufacturing sector; (2) the service sector and transport facilities grow; (3) increased appreciation for quality of life and the rise of what can be called an environmental sector; and (4) rise of the information sector. The cyclus is marked by spatial concentration at first, followed by a deconcentration later. The predictions of this urban dynamics model are accordingly described as structurally determined. The actual urban configuration at any one time is considered to be the result of an interaction between internally structuring forces and externally intervening forces.

Analysts isolate and study the underlying interactions and changes in different analytical frameworks ranging from the partial and more specific to the more general. Furthermore, while many frameworks emphasize the spatial dimension, others emphasize the sectoral. Our objectives are to present an analytical framework that focuses on the economy-wide circular flow and sectoral interactions, and demonstrate its usefulness for understanding recent changes in the urban development of the small and developed economy of The Netherlands.

Urbanization studies for The Netherlands [3] suggest that the Dutch urban system is in stage (3) of the cyclus. This stage is marked by spatial deconcentration, which means a shift of people and jobs from cores (central towns) to rings (surrounding suburban municipalities). Some features of this stage include a rapid rise in energy prices and a contraction of average family size, while public transport, town renovation and spatial planning are given more weight in government policy. The Dutch urban system saw a deconcentration of population which peaked in the early 1970s and has since then declined, as well as a movement towards stage (4), in which we see a more balanced development of central towns and suburban areas (revitalization or reurbanization policy), a widespread computerization of society, increased attention to small-scale industry and a structural increase of leisure time.

More specifically, during the 1960 s and early 1970 s, a period with considerable economic growth, there was a strong emphasis in The Netherlands on suburbanization, which led to the decline of cores and even of entire agglomerations. The introduction of growth towns in ring areas was important for the increasing population in the suburban municipalities. A change in the downward trend was observed at the end of the 1970s which coincided with the gloomy economic prospects of towering unemployment figures and weak (negative) economic growth. In the course of the 1980 s, which were years of cautious recovery of the Dutch economy, there were once again tendencies towards a slight increase in deconcentration.

Policy studies [2] show that in these years there was a change in the growth towns in the sense of a different market-oriented policy aimed at consolidating the foundations of the competitive 
position of the agglomeration for which one would try to attract high-grade companies, high-income groups and tourists. The town is looked upon as an enterprise to be managed efficiently and whose continuity must be safeguarded. Evidence on the success of growth towns' policy is mixed. In some instances, cities are not deconcentrating, while in other instances city deconcentration is occurring.

The studies mentioned above approach the problem of urban dynamics and reach their conclusions using primarily frameworks that lay emphasis on the spatial settlement of households and business in different urbanization levels. However, these studies are disadvantaged by paying less attention to the economy-wide linkages which couple activities and households at different levels of urbanization. The objective of this paper is to attack this disadvantage by modelling the economy-wide circular flow as a general equilibrium framework. This will allow treating economy-wide linkage effects and explore growth and distributionary tendencies of changing urbanization patterns over an intermediate period of time.

The questions addressed are: How can internally structuring forces and externally intervening forces working together in the economy-wide circular flow, explain urban dynamics during the 1980 s in the Netherlands? And when and where were the externally intervening forces more significant than the internally structuring forces? The hypothesis which we pose is that while the external forces are statistically more significant than the internal forces in shaping urban dynamics, the combination of the two forces is different for different urbanization levels.

To that purpose, we construct and analyze a social accounting matrix (SAM) of The Netherlands for two-periods. This SAM will distinguish between household groups classified by six urbanization levels. In general, the SAM is a circular flow register of incomings and outgoings of households, firms, sectors, government and the rest of the world. The origins of the idea go back to Quesnay's Tableau Economique in 1758. The idea was revived only 200 years later by R. Stone, among others. Today, there are such matrices for most countries and sometimes with regional disaggregations. For applications of SAM to comparative statistics, regional and interregional analysis see Refs $[1,6,7,10]$.

The SAM is seen as a helpful tool in: (1) the setting up of national and regional statistical accounts, and discovering and correcting for inconsistencies; (2) conducting diagnostic analysis on the interrelations between components of the circular flow; (3) initialization of applied general equilibrium models; and (4) being a square matrix. The SAM can be converted into a static general equilibrium model of the economy, which can help explain on the internal and external mechanisms of the economy.

The current paper focuses on the conversion of the SAM into a circular flow model. After introducing the construction and structure of the SAM, multipliers of the SAM circular flow model are analyzed to show the impact of various injections on the growth of the six urbanization levels in two different years, namely 1981 and 1985. Finally, a decomposition of urban growth performance in terms of internal and external forces is done over the 4 years.

\section{STRUCTURE AND CONSTRUCTION OF A SAM FOR THE NETHERLANDS}

A SAM is basically a transformation of the circular flow in an exchange economy into a matrix of transactions amongst various agents, as in Table 1. In the rows of such a matrix, we find several types of accounts: (1) the products account; (2) the factors account, consisting of labour income and other income from profits, interest etc.; (3) the institutions' current account for, respectively, households, firms, government and social insurance, as well as one aggregrate institutional capital account; (4) the production activities account; and (5) the rest of the world account (ROW). The columns are ordered similarly. Transactions between these factors are represented by the filled cells in correspondence with the circular flow. A particular row lists receipts of a given group of actors-or incomings, while a particular column lists corresponding expenditures-or outgoings. For example, in Table 1, row 4 is equivalent to the total receipts of the households, giving, from left to right, receipts from wages $(155,080)$, profits $(57,818)$, transfers from government $(21,520)$, from social security $(75,100)$ and from abroad $(-1078)$. Column 4 gives the expenditure of the households.

Such an aggregate SAM of The Netherlands for 1981 is constructed entirely from published 
Table 1. The social accounting matrix of The Netherlands, 1981, in millions of guilders"

\begin{tabular}{|c|c|c|c|c|c|c|c|c|c|c|c|}
\hline Expen & $\begin{array}{l}\text { es/receipts } \\
\text { Products } \\
1\end{array}$ & $\begin{array}{c}\text { Wages } \\
2\end{array}$ & $\begin{array}{c}\text { Profits } \\
3\end{array}$ & $\begin{array}{c}\text { Household } \\
4\end{array}$ & $\begin{array}{c}\text { Firm } \\
5\end{array}$ & $\begin{array}{c}\text { Govt } \\
6\end{array}$ & $\begin{array}{c}\text { Social } \\
\text { Security } \\
7\end{array}$ & $\begin{array}{c}\text { Capital } \\
8\end{array}$ & $\begin{array}{c}\text { Activities } \\
9\end{array}$ & ROW & Total \\
\hline 1 & & & & 213,230 & & 60,100 & 2650 & & & & 275,980 \\
\hline 2 & & & & & & & & & 20,1530 & 110 & 201,640 \\
\hline 3 & & & & & & & & & 82,798 & -1070 & 81,728 \\
\hline 4 & & 155,080 & 57,818 & & & 21,520 & 75,100 & & & -1078 & 308,440 \\
\hline 5 & & & 17,960 & & & & & & & & 17,960 \\
\hline 6 & 15,424 & & 5010 & 44,150 & 11,100 & & & 5811 & 11,053 & -1378 & 91,170 \\
\hline 7 & & 46,560 & 940 & 19,580 & & 9850 & & & & -590 & 76,340 \\
\hline 8 & & & & 31,480 & 6860 & -300 & -1410 & & 35,617 & -7756 & 64,491 \\
\hline 9 & 223,764 & & & ? & & & & 46,246 & 194,260 & 189,075 & 653,348 \\
\hline 10 & 36,792 & & & & & & & 12,431 & 128,090 & 14,928 & 192,241 \\
\hline Total & 275,980 & 201,640 & 81,728 & 30,8440 & 17,960 & 91,170 & 76,430 & 64,491 & 653,348 & 192,241 & $1,963,338$ \\
\hline
\end{tabular}

'In 1981, the exchange rate was U.S. $\$ 1.00$ to 2.67 Dutch guilders. In 1995 , U.S. $\$ 1.00=1.60$ Dutch guilders.

estimates of the national accounts for that year. There are several options for the disaggregation of the SAM depending on available data and the purpose of the analysis, cf. Ref. [8]. The SAM in this paper has been disaggregated further into seven products, two factors of production and six household groups who receive and spend incomes. They are classified by their residence in various degrees of urbanization. The available statistics make the following classification feasible:

1. Rural municipalities (r.m.); with more than $20 \%$ of the labour force active in agriculture.

2. Urbanized rural municipalities (u.r.m.); with less than $20 \%$ of the labour force active in agriculture.

3. Dormitory towns (d.t.); with at least $30 \%$ non-residents.

4. Small towns (s.t.); with $10,000-30,000$ inhabitants.

5. Medium-sized towns (m.s.t.); with 50,000-100,000 inhabitants.

6. Large towns (1.t.); with more than 100,000 inhabitants, i.e. cities.

In addition to these, there are accounts for firms, government, social insurance, an aggregate capital account, 10 sectors of production activities, and the rest of the world. The result is a matrix of 30 rows $\times 30$ columns, as seen in Table 2 .

The data required for disaggregation include: (a) the household budget survey produced by the Central Bureau of Statistics [4], used to break up the household account into the six urbanization groups, specifying their incomes by source and expenditures by type of product (the entries in the SAM reflect the fact that the household budget surveys do not consider income transfer between household groups, which is a limitation); (b) the input-output table, in order to disaggregate the production activities; and (c) an initial converter table, to transform a classification by products into a classification by sector. The same SAM has been constructed for 1985 at 1985 prices. (See Appendix Table A1 and Table A2).

In the following, we seek to sketch but a few characteristics of the changes the household groups underwent during the period 1981-85. One interesting phenomenon involves the variance and change in the average household size over the different urbanization levels. In 1981, the size varied from 3.5 for households in the rural municipalities to 2.3 for households in the large towns. During the period 1981-85 we see, for each urbanization level, a slight decrease of the average household size. This decrease in size is a general trend in The Netherlands and is predicted to continue partly due to aging and partly to a preference by the young for a one-person household.

\section{ANALYSIS OF SAM MULTIPLIERS}

The use of a SAM as a model that generates multipliers can be demonstrated from a very simple example. Take the simplest Keynesian model, which contains a consumption equation relating consumption $C$ to income $Y$, and an equation defining income as consumption $C$ plus investment 
S. I. Cohen

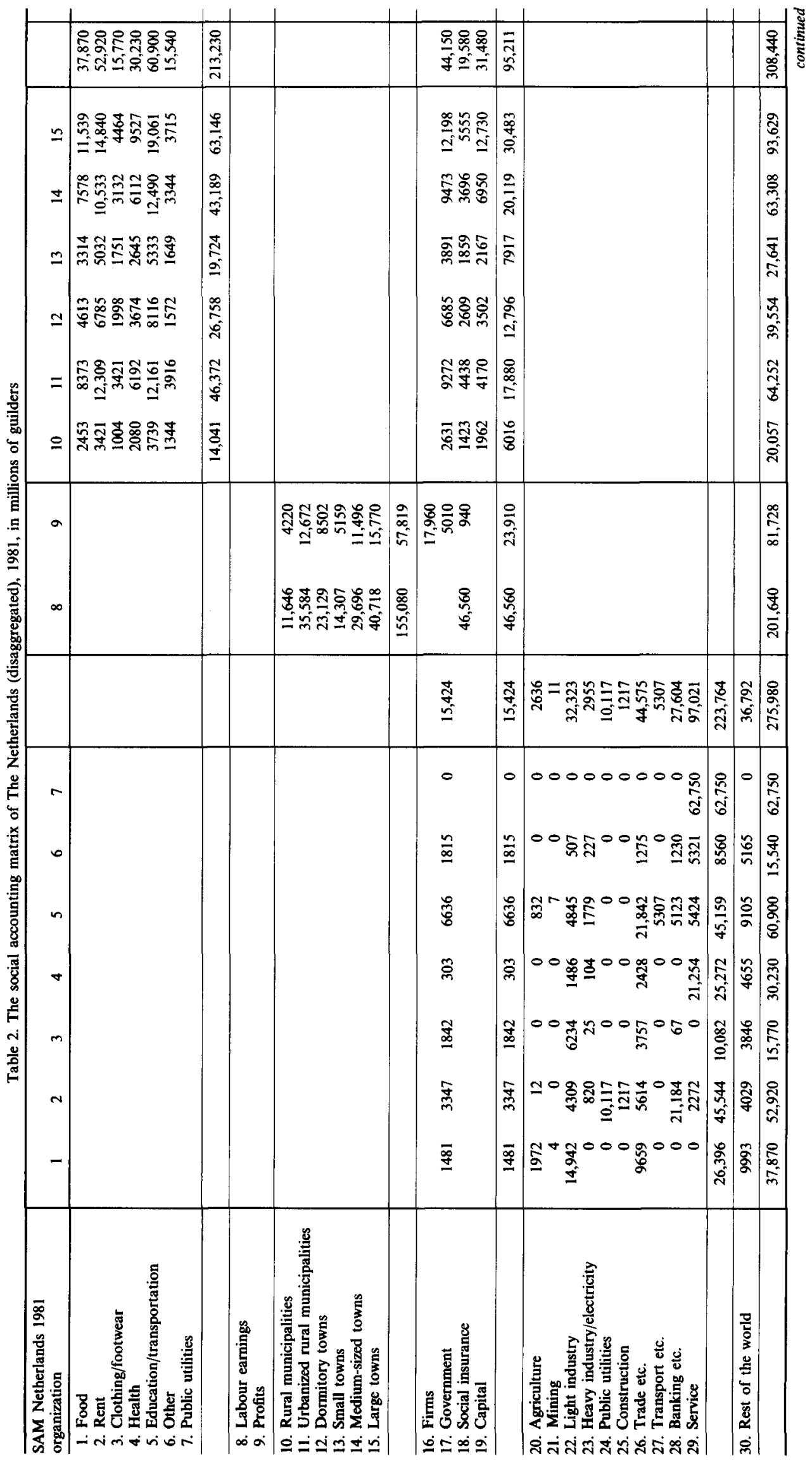




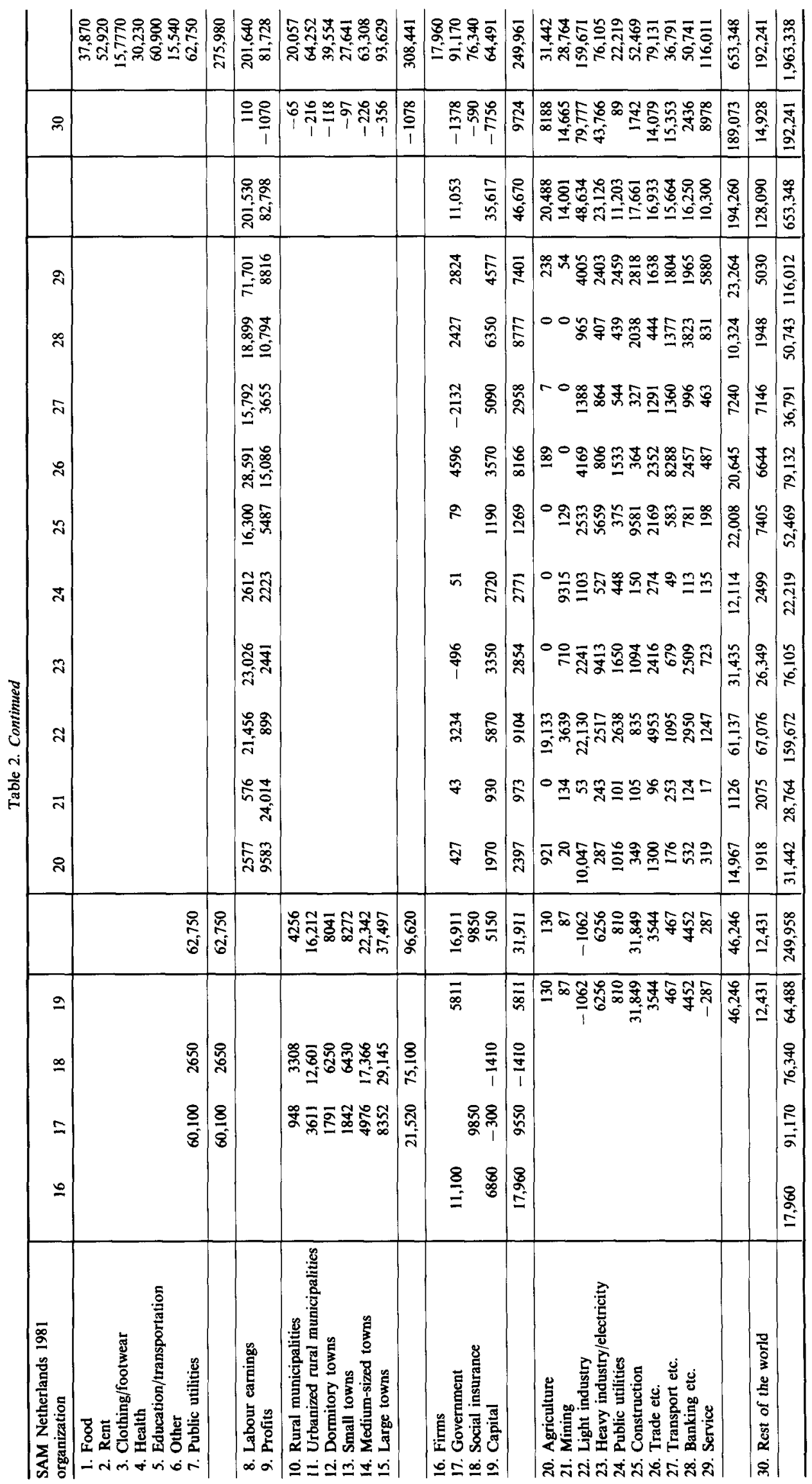


I. That is:

$$
\begin{gathered}
C=c Y \\
Y=C+I
\end{gathered}
$$

This is a model of two equations in two endogenous (unknown) variables of $C$ and $Y$, where $I$ is an exogenous (given) variable. The model can be written as a square matrix which is then inverted to give the Keynesian multipliers, i.e. the effect of an increase in $I$ on $Y$ [i.e. in this case $1 /(1-c)$ ].

In this way, many models have been developed with their own characteristic multipliers. In one of the most frequently used models, the input-output model, an endogenous vector of sectoral production (y) can be predicted from a matrix of input-output coefficients $A$ and a vector of exogenous final demand $x$ as in eqn (3).

$$
y=A y+x=(I-A)^{-1} x=M_{\mathrm{a}} x,
$$

where $M_{\mathrm{a}}$ is the Leontief multiplier matrix.

Now, the interesting case arises when the SAM is also a square matrix, and, as such, it represents a model of the economy. By appropriate partition and inversion of this square matrix, it is also possible to derive SAM-multipliers, which are more comprehensive than those of Keynes and Leontief together; this, because the SAM contains the whole circular flow.

Several steps are required in converting the SAM into a model. First, a sub-division of the $30 \times 30$ SAM between endogenous $y$ and exogenous $x$ variables is required. We shall assume for a country like The Netherlands that the columns of government expenditure, social insurance and rest of the world are exogenous. Why these three columns? Because government behaviour cannot apparently be explained in terms of demand and supply or utilities and availabilities in the same sense as earnings and expenditure of households are explained economically, even though it is not denied that there have been analytical advances in endogenizing government behaviour.

Transfers under the social security system in the Netherlands are legally determined. They were considered in the 1970 s to be a given constant. The level and coverage of social security payments have since then become controversial. Social security payments are generally viewed as more the result of political pressures than of economic motivations.

Finally, for a small open-economy country like The Netherlands, it is most realistic to consider the demand pattern of the rest of the world as exogenous.

By separating the influence of these three externally intervening forces from the rest of the economy-government expenditure, social security and exports-it becomes feasible to study the rest of the economy consisting of factors, households, firms and sectors, as an internally functioning economic structure. In a sense, the externally intervening forces are the impulses that drive the economy, while the internally functioning economic structure-via factor earnings, consumption and investment of households, and intersectoral relations of firms-give shape to the outcome.

As a result of the above exogenous assignments, variables belonging to the remaining 27 accounts are endogenous, $y$. These consist of variables of the seven product accounts, as well as those of the two factor accounts, the current institutions account pertaining to six household types distinguished by urbanization level, those of the firms, the capital institution account and, finally, the 10 sectoral activities.

This particular sub-division into endogenous and exogenous variables will allow the study of multiplier effects of exogenous actions in the forms: (1) institutional transfers to households by urbanization level; and of (2) sectoral injections. We shall be interested in tracing the income effects on households located by urbanization level $h$ and the output effects on sectoral activities $i$.

Secondly, the flows in the endogenous matrix are divided by their respective totals, columnwise, to give the matrix of average propensities $S$.

Thirdly, the vector of endogenous variables $y$ can now be solved from matrix $S$ and exogenous variables $x$ in eqn (4), to give the SAM multiplier matrix $M_{s}$ :

$$
y=S y+x=(I-S)^{-1} x=M_{\mathrm{s}} x .
$$

The portions of $M_{\mathrm{s}}$ in which we are primarily interested are denoted by $M_{\mathrm{s}, \mathrm{hh}}$ and $M_{\mathrm{s}, \mathrm{h}}$, which stand for the effects of income transfers to households $h$ on income of households $h$, and output by sector 
Table 3. Average multiplier effects of institutional transfers, $\overline{\mathbf{M}}_{5, \mathrm{hh}}$ and $\overline{\mathbf{M}}_{\mathrm{s}, \mathrm{hh}}$, and sectoral injections, $\overline{\mathbf{M}}_{\mathrm{s}, \mathrm{hi}}$ and $\overline{\mathbf{M}}_{\mathrm{s,hh}}$ The Netherlands 1981

\begin{tabular}{|c|c|c|c|c|c|}
\hline & \multirow[b]{2}{*}{$\begin{array}{c}\text { Actual shares } \\
\text { in total } \\
\text { (1) }\end{array}$} & \multicolumn{2}{|c|}{ Average of all institutional transfers } & \multicolumn{2}{|c|}{ Average of all sectoral injections } \\
\hline & & $\begin{array}{l}\text { Multiplier share } \\
\text { in total } \\
\text { (2) }\end{array}$ & $\begin{array}{c}\text { RDM } \\
(3)=(2) /(1)\end{array}$ & $\begin{array}{l}\text { Multiplier share } \\
\text { in total } \\
\text { (4) }\end{array}$ & $\begin{array}{c}\text { RDM } \\
((5)=(4) /(1)\end{array}$ \\
\hline \multicolumn{6}{|l|}{ Income by urbanized level } \\
\hline Rural municipalities & 6.50 & 7.45 & 1.15 & 7.43 & 1.14 \\
\hline Urban rural municipalities & 20.83 & 22.65 & 1.09 & 22.57 & 1.08 \\
\hline Dormitory towns & 12.82 & 14.85 & 1.16 & 14.84 & 1.16 \\
\hline Small towns & 8.96 & 9.14 & 1.02 & 9.12 & 1.02 \\
\hline Medium towns & 20.53 & 19.36 & 0.94 & 19.41 & 0.95 \\
\hline Large towns & 30.36 & 26.54 & 0.87 & 26.62 & 0.88 \\
\hline Total & 100.00 & 100.00 & & 100.00 & \\
\hline Average income multiplier & & $\overline{\mathrm{M}}_{\mathrm{s}, \mathrm{hh}}=1.457$ & & $\overline{\mathbf{M}}_{\mathbf{s}, \mathrm{hi}}=$ & \\
\hline \multicolumn{6}{|l|}{ Output of sectors } \\
\hline 1. Agriculture & 4.81 & 3.25 & 0.68 & 4.16 & 0.86 \\
\hline 2. Mining & 4.40 & 2.82 & 0.64 & 6.36 & 1.44 \\
\hline 3. Light industry & 24.44 & 17.68 & 0.72 & 18.51 & 0.76 \\
\hline 4. Heavy industry & 11.65 & 6.08 & 0.52 & 9.22 & 0.79 \\
\hline 5. Public utilities & 3.40 & 5.43 & 1.60 & 5.08 & 1.49 \\
\hline 6. Construction & 8.03 & 12.84 & 1.60 & 16.44 & 2.05 \\
\hline 7. Trade & 12.11 & 19.30 & 1.59 & 14.46 & 1.19 \\
\hline 8. Transport & 5.63 & 5.17 & 0.92 & 5.63 & 1.00 \\
\hline 9. Banking & 7.77 & 13.90 & 1.79 & 11.34 & 1.46 \\
\hline 10. Services & 17.76 & 13.52 & 0.76 & 8.79 & 0.50 \\
\hline Total & 100.00 & 100.00 & & 100.00 & \\
\hline \multicolumn{2}{|l|}{ Average output multiplier } & \multicolumn{2}{|c|}{$\overline{\mathbf{M}}_{\mathrm{sih}}=1.333$} & \multicolumn{2}{|c|}{$\overline{\mathbf{M}}_{\mathrm{s}, \mathrm{ij}}=2.271$} \\
\hline
\end{tabular}

i; while $M_{\mathrm{s}, \mathrm{hi}}$ and $M_{\mathrm{s}, \mathrm{i}}$ represent the effects of demand injections in sector i on incomes of households $\mathrm{h}$ and output by sector $\mathrm{i}$, respectively.

Besides the size of the multipliers, it is interesting to know: (1) how the predicted income multiplier effect will be distributed on the households by residence, and how the predicted output multiplier effect will be distributed on the sectors of production; and (2) how they compare to the actual distribution of income on households and actual distribution of output on sectors, respectively. We use for such a measure the Relative Distributive Measure (RDM), as defined in Ref. [5]. It is the quotient of the percentage distribution of the predicted individual multiplier effects on households (sectors) to the actual share of income of households (output of sectors) in the total household income (total sectoral output), and thus reflects the long-term income (output) growth bias of the economy. For values of $\operatorname{RDM}<1,>1$ and $=1$, there are positive, negative and neutral redistributive effects, respectively. For example, a predicted multiplier share of $27 \%$ and an actual share of $30 \%$ as far as household income of large towns is concerned gives an RDM of 0.87 , which is an indication of a negative growth bias, as shown in Table 3. In the next section, we shall discuss to which direction the income and output growth patterns of institutional transfers and sectoral injections are biased in The Netherlands.

Table 3 gives average values of SAM multipliers for 1981 of institutional transfers and their relative distribution on households and sectors, $M_{\mathrm{s}, \mathrm{hh}}$ and $\boldsymbol{M}_{\mathrm{s}, \mathrm{hi}}$, and, similarly, those of sectoral injections under $M_{\mathrm{s}, \mathrm{hi}}$ and $M_{\mathrm{s}, \mathrm{il}}$.

It is interesting to note from the second column of Table 3 that irrespective of the urbanization level to which institutional transfers take place, the generated income multiplier effect of one unit of transfer is about 1.45 units. Results, not taken in the table, cf. Ref. [9] show very little variance; namely, between a low value of 1.44 in the case of an injection to dormitory towns and a high value of 1.47 in the case of an injection to large towns, i.e. cities.

The percentage distribution of the generated income multiplier effect shows cities to benefit most, $26 \%$, and rural municipalities least, $7 \%$. Results, not taken in the table, show also that almost the same pattern of distribution of benefits on the six urbanizations is repeated irrespective of the urbanization level to which the initial transfer is directed.

In the fourth column, Table 3 shows a sectoral injection of 1.0 to generate an average income multiplier of 0.77 , which is distributed on the urbanization levels along the same pattern mentioned previously.

In the first column, the table lists the actual distributions of household income by urbanization level and output by sector. It is then possible to compute RDM, which is the division of the 
predicted share by the actual share. The results show that rural municipalities and dormitory towns are experiencing the highest growth bias with RDM values of 1.15 and 1.16, respectively. Large towns are mostly disfavoured $(\mathrm{RDM}=0.87)$. The results support the hypothesis of a built-in decline bias for large towns in favour of outskirts. More or less, the same tendencies are obtained for multipliers and RDM relating to sectoral injections.

The lower part of the table gives results on output multipliers and their distribution on sectors. Results show a sectoral growth bias favourable to construction, public utilities, banking, mining and trade, all with RDM $>1.0$ and an unfavourable bias for services, light and heavy industry. This would indicate a confirmation of the hypothesis that urban development in The Netherlands, which has already passed cyclus stages 1 and 2, was, during the 1980s, in stage 3 and approaching stage 4, which is consistent with Ref. [3].

The availability of the SAMs for 1981 and 1985 permits an investigation of how the above multiplier effects have changed, admittedly though, over a relatively short period of time. The analysis may be limited by the fact that both SAMs are in current prices. The extent of this limitation cannot yet be fully determined. In this respect, it is comforting to know that between 1981 and 1985 the annual increases of the Paasche price indices for the categories of consumption, investment and the GDP were 3.9, 2.8 and $3.6 \%$, respectively, which are low and reasonably close to each other.

Table 4 gives the SAM multipliers for 1985. It can be restated that in 1981 an institutional transfer of 1 million guilders (m.g.) has lead to an average income multiplier amounting to 1.457 m.g. and an output multiplier of $1.333 \mathrm{~m} . \mathrm{g}$. In contrast, in 1985 an institutional transfer of $1 \mathrm{~m} . \mathrm{g}$. would generate, on average, an income multiplier of $1.445 \mathrm{~m} . \mathrm{g}$., which is $0.8 \%$ less than in 1981 , and an output multiplier of 1.282 , which is $3.8 \%$ less than in 1981 .

Over the 4 years there has been, in fact, only a slight deterioration of both multipliers. But this begs the question: did the relative distribution of the income effects on the households and of the output effects on the sectors remain the same? For this purpose, we shall compare the RDM indicators for 1985 with those of 1981.

Taking first the relative distribution of the income multiplier, we note an increase of the values of RDM for households in small towns (from 1.02 to 1.09) and in middle-sized towns (from 0.95 to 0.99 ). This was accompanied by a reduction of RDM for households in the other urbanizations; particularly in the rural municipalities, dormitory towns and large towns, experiencing reductions of about 4,8 and $4 \%$, respectively. The obtained results show that the period of 1981-1985 was

Table 4. Average multiplier effects of institutional transfers, $\overline{\mathrm{M}}_{\mathrm{s} \text {,h }}$ and $\overline{\mathrm{M}}_{\mathrm{s}, \mathrm{h}}$, and sectoral injections, $\overline{\mathrm{M}}_{\mathrm{s}, \mathrm{hi}}$ and $\overline{\mathrm{M}}_{\mathrm{s} \text {.i }}$ The Netherlands, 1985

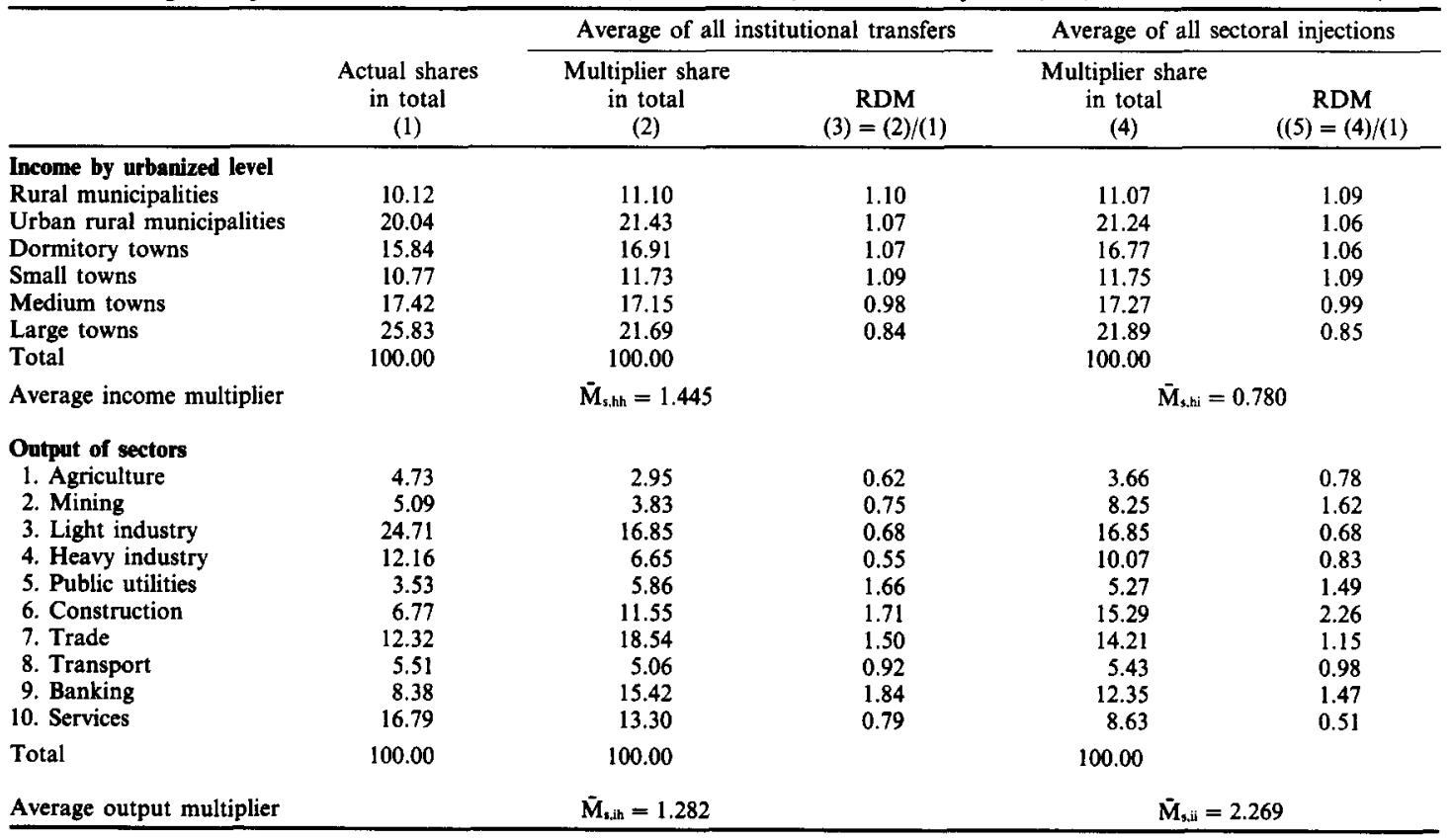


characterized by convergence tendencies in income growth bias of the various urbanization levels. In this regard, note especially that the decline bias for large towns appears to have been intensified, with RDM declining from 0.88 to 0.84 .

Taking next the relative distribution of the output multiplier on sectors of production, we see here that there is much similarity between 1985 and 1981. In The Netherlands there is a growth bias towards four sectors: banking, construction, public utilities and trade, with values of RDM in 1985 above 1.50. Except for trade, the other three sectors show higher rates of their RDM in 1985 than in 1981 . The increases vary between $2.8 \%$ for banking and $6.9 \%$ for construction. The other sectors have a decline basis. Thus, in 1985, the urbanization sectors of heavy industry and agriculture were mostly disfavoured, with values of RDM of 0.55 and 0.62 (in 1981, these were 0.52 and 0.68 , respectively). In 1985 , light industry and mining were also experiencing low RDM values of 0.68 and 0.75 (where, in 1981 these values were 0.72 and 0.64 , respectively).

The noted growth and decline bias in the contexts of household incomes at urbanization levels and sectoral output feed each other. Large towns with an income decline bias ( $R D M=0.85$ ) have relatively more of such sectors as light industry and services with RDM's of 0.68 and 0.51 , respectively. The demands for these sectors is likewise more dependent on the prosperity of the large towns than on other urbanization levels.

It requires noting that the Keynesian, Leontief and SAM models share together the common feature that they are basically demand representations of the economy. The multiplier effects from these models do not consider the supply side. It is assumed that supply adjusts to demand, i.e. that there are no capacity restrictions that will obstruct the realization of the potential multiplier effect. Accordingly, the role of investment in these models is confined to that of enhancing the purchase of capital goods, and not of adding to the productive capacity. Whether the potential multiplier effects of impulses will be realized in increased quantities in full or in part depends on the elasticity of supply. If the size of the impulse is relatively small, which is usually the case, these multipliers can still be seen to represent realizable quantity effects with little leakage into price inflationary effects.

\section{DECOMPOSITION OF PAST PERFORMANCE}

SAM multipliers of The Netherlands for the periods 1978 and 1981, as reported in Ref. [5], showed diminishing effects over time for all the sectors (except for public utilities and banking). We see once again in a later period between 1981 and 1985 diminishing multiplier effects over time for most of the sectors. Exceptions are mining, heavy industry, public utilities and banking. The situation for households is less clear because only three out of six urbanizations show negative multiplier effects, namely household groups in the urbanized rural municipalities, middle sized towns and large towns.

The diminishing income and output multiplier effects between 1981 and 1985 can be interpreted as a weakening of the endogenous circular flow mechanisms in the economy.

Since The Netherlands had experienced some economic growth between 1978 and 1981, and still a greater economic growth between 1981 and 1985, there must have been during these years a strengthening of the positive exogenous effects so as to overcompensate for the weakened endogenous effects, producing the realized economic growth. This implies that there has been an increased dependence on the exogenous variables in influencing the course of the economy. The exogenous variables, it should be recalled, are those of the government sector, social security, and the rest of the world. The hypothesis of a weakening of the internally structuring forces-the endogenous multiplier effects - and an increased dependence of the economy on externally intervening forces-the exogenous effects-are those treated here.

The availability of the two SAMs for 1981 and 1985 allows a decomposition of the performance of the economy in the medium term into that part which is due to changes in SAM multipliers and that part due to changes in the exogenous variables.

Recall that we have solved the vector of endogenous variables $y$ from eqn (4):

$$
y=S y+x=(I-S)^{-1} x=M_{\mathrm{s}} x
$$

where $M_{\mathrm{s}}$ is the aggregate multiplier matrix and $x$ is the vector of exogenous variables. Rewriting 
Table 5. An explanation of changes in urbanization income and sectoral output between 1981 and 1985 in terms of changes in exogenous variables and SAM multipliers, The Netherlands

\begin{tabular}{|c|c|c|c|c|c|c|c|c|c|}
\hline & \multirow[b]{2}{*}{$\begin{array}{l}\text { Overall } \\
\text { (1) }\end{array}$} & \multicolumn{4}{|c|}{ Changes in millions of current Dutch guilders } & \multirow[b]{2}{*}{$\begin{array}{c}\text { ROW } \\
(6)\end{array}$} & \multirow[b]{2}{*}{$\begin{array}{c}\text { Overall } \\
(7)\end{array}$} & \multicolumn{2}{|c|}{ Percentages } \\
\hline & & $\begin{array}{l}\text { Due to } \\
\text { multiplier } \\
\text { (2) }\end{array}$ & $\begin{array}{l}\text { Due to } \\
\text { exogenous } \\
\text { (3) }\end{array}$ & $\begin{array}{l}\text { Of which } \\
\text { government } \\
\text { (4) }\end{array}$ & $\begin{array}{c}\text { Social } \\
\text { security } \\
(5)\end{array}$ & & & $\begin{array}{l}\text { Multiplier } \\
\text { (8) }\end{array}$ & $\begin{array}{c}\text { Exogenous } \\
\text { (9) }\end{array}$ \\
\hline \multicolumn{10}{|l|}{ Urbanization income } \\
\hline Rural municipality & 16,695 & 7493 & 9202 & 2289 & 3857 & 3056 & 83.24 & 37.36 & 45.88 \\
\hline Urban rural municipality & 8550 & -3065 & 11,615 & 3148 & 2525 & 5942 & 13.31 & -4.77 & 18.08 \\
\hline Dormitory towns & 18,011 & 4009 & 14,002 & 3571 & 5763 & 4667 & 45.54 & 10.14 & 35.40 \\
\hline Small towns & 11,477 & 5196 & 6281 & 1655 & 1345 & 3281 & 41.52 & 18.80 & 22.72 \\
\hline Medium towns & -22 & -5189 & 5167 & 1849 & -1554 & 4873 & -0.03 & -8.20 & 8.17 \\
\hline Large towns & 213 & $-10,964$ & 11,178 & 4157 & 885 & 6135 & 0.23 & -11.71 & 11.94 \\
\hline Total & 54,924 & -2521 & 57,444 & 16,688 & 12,821 & 27955 & 17.81 & -0.82 & 18.62 \\
\hline \multicolumn{10}{|l|}{ Sectoral output } \\
\hline Agriculture & 5233 & -2265 & 7498 & 451 & 367 & 6680 & 16.64 & -7.20 & 23.85 \\
\hline Mining & 10,769 & 3962 & 6806 & 571 & 539 & 5696 & 37.44 & 13.77 & 23.66 \\
\hline Light industry & 32,075 & -6556 & 38,631 & 2459 & 2250 & 33922 & 20.09 & -4.11 & 24.19 \\
\hline Heavy industry & 18,270 & 2208 & 16,062 & 154 & 1833 & 14,075 & 24.01 & 2.90 & 21.10 \\
\hline Public utilities & 5191 & 859 & 4331 & 901 & 798 & 2632 & 23.36 & 3.86 & 19.49 \\
\hline Construction & 54 & -5122 & 5178 & -416 & 3788 & 1805 & 0.10 & -9.76 & 9.87 \\
\hline Trade & 16,480 & -2503 & 18,984 & 2389 & 2624 & 13,970 & 20.83 & -3.16 & 23.99 \\
\hline Transport & 6007 & -753 & 6760 & 730 & 714 & 5317 & 16.33 & -2.05 & 18.37 \\
\hline Banking & 14,315 & 4540 & 9773 & 2009 & 2225 & 5539 & 28.21 & 8.95 & 19.26 \\
\hline Services & 14,292 & -774 & 15,065 & 6714 & 1950 & 6401 & 12.32 & -0.67 & 12.99 \\
\hline Total & 122,685 & -6404 & 129,088 & 15,962 & 17,088 & 96,038 & 18.78 & -0.98 & 19.76 \\
\hline
\end{tabular}

Note: $(7)=(1) /$ value of variable in $1981 .(8)=(2) /(1) \times(7) .(9)=(3) /(1) \times(7)$.

this equation for two periods of 1981 and 1985 and subtracting 1981 from 1985 to give the change in the endogenous variables $\Delta y$, yields eqn (5):

$$
\Delta y=y_{85}-y_{81}=M_{s, 85} x_{85}-M_{\mathrm{s}, 81} x_{81}
$$

Changes in the endogenous sector can be explained in terms of two effects: a change in the multiplier matrix $\left(M_{\mathrm{s}, 85}-M_{\mathrm{s}, 81}\right)$ and a change in the exogenous vector $\left(x_{85}-x_{81}\right)$. The assumption of a zero value for one effect allows for measurement of the other. This is done by adding, subtracting and simplifying terms to give eqn (6):

$$
\Delta y=M_{\mathrm{s}, 85} x_{85}-M_{\mathrm{s}, 81} x_{81}=M_{\mathrm{s}, 85} x_{85}-M_{\mathrm{s}, 85} x_{81}+M_{\mathrm{s}, 85} x_{81}-M_{\mathrm{s}, 81} x_{81}=M_{\mathrm{s}, 85} \Delta x+\Delta M_{5} x_{81}
$$

As a result, the change in an endogenous variable is decomposed into a change in exogenous variables (at constant SAM multipliers), and a change in SAM multipliers (at constant exogenous variables).

Table 5 applies the above factorization to the SAMs of 1981 and 1985 in an effort to explain the changes in overall and sectoral output and in overall income and its distribution across the different household groups distributed by urbanization level. Results show that total income and total output increased by 17.8 and $18.8 \%$, respectively. This is basically due to the exogenous change of $18.7 \%$ for total income and of $19.8 \%$ for total output, together with a minor decrease in the percentage change of the multiplier $0.8 \%$ resp. $1.0 \%$.

We can see from Table 5 that during 1981-1985 the income performance of household groups living in the rural municipalities of The Netherlands were the best in spite of the previously observed unfavourable relative income distribution bias. Income growth of this urbanization level amounted to $83.2 \%$ as compared to a national average of $17.8 \%$. This is the result of a positive change in the multiplier effect over time of $37.4 \%$ and an even higher positive change in the exogenous effect of $45.9 \%$ as compared to the national averages of -0.8 and $18.6 \%$, respectively. It can be asserted that both the endogenous and exogenous forces have worked in favour of the households in rural municipalities during the period considered.

Households in urbanized rural municipalities, middle sized towns and large towns experienced least favourable performance. Total income of middle sized towns decreased in 1981-1985 by $0.03 \%$, which was due to a deterioration of the multiplier component of $-8.2 \%$ and to an increase of the exogenous stimulus of $8.2 \%$. Total income of households in large towns changed little in 1981-1985-a nominal growth of $0.23 \%$-which was due to a deterioration of the multiplier component of $-11.7 \%$ and an increase in the exogenous stimulus of $11.9 \%$. Total income of 
households in urbanized rural municipalities increased by $13 \%$, consisting of a decline in the multiplier effect of $-5 \%$ and a rise in the exogenous effect of $18 \%$.

Summarizing, we see that the endogenous multiplier effects work against the urbanized rural municipalities, middle-sized towns, and large towns, in that they show negative multiplier effects of $-4.8,-8.2$ and $-11.7 \%$, respectively. Furthermore, the contributions of the exogenous effects to overall growth at $18.1,8.2$ and $11.9 \%$, respectively, are also less than that for a national growth at $18.6 \%$.

Table 5 also allows for a decomposition of the exogenous stimulus by source: namely, the government, social security and the rest of the world. What, then, are the consequences of the exogenous stimuli by source on urbanizational growth in the period 1981/1985? In the first place, in absolute amounts, the exogenous stimuli of the government are particularly beneficial for households in large towns, dormitory towns and urbanized rural municipalities, who are clearly associated with public employment and related jobs. The exogenous stimuli of social security are found to favour dormitory towns, rural municipalities and urbanized rural municipalities, where, presumably, old-age pensioners live, while the exogenous stimuli of the rest of the world favour large towns, urbanized rural municipalities and middle-sized towns.

Realized growth of mining (37\%) and banking (28\%) are remarkably high as compared to low figures of services $(12 \%)$ and construction (almost zero growth). The endogenous multiplier effects have favoured mining and banking as reflected in positive multiplier changes for mining $(13.77 \%)$ and banking $(8.95 \%)$. Further, public utilities $(3.86 \%)$ and heavy industry $(2.90 \%)$ have benefited. For agriculture and construction we note the highest negative multiplier changes of -7.20 and $-9.76 \%$, respectively. The exogenous changes are positive for all sectors and have varied between $9.87 \%$ for construction and $24.19 \%$ for light industry. Table 5 shows once again that the stimulus to growth differs across sectors, with growth generally more dependent on exogenous than endogenous mechanisms.

With respect to exogenous stimulus by source the results indicate the relative importance of government stimulus for services and light industry, of social security for construction and trade, and the external world for light and heavy industry and trade.

It must be kept in mind, however, that eqn (5) and (6) can alternatively be reformulated to give a decomposition of performance starting from a different base (year), as in eqn (7):

$$
\Delta y=\Delta M_{\mathrm{s}} x_{85}+M_{\mathrm{s}, 81} \Delta x
$$

A more general formula would be:

$$
\Delta y=\Delta M_{\mathrm{s}} x_{81}+M_{\mathrm{s}, 81} \Delta x+\Delta M_{\mathrm{s}} \Delta x
$$

However, the results obtained from application of eqn (7) do not vary much from those of eq (6) and, hence, to save space, are not reported here. The similarity of results in using eq (6) and (7) offers some evidence that selection of a base year, 1981 or 1985 , for decomposition of past performance does not significantly influence the obtained results. Consequently, one can speculate that the results in this section may not have been much different if the SAMs were expressed in constant prices.

\section{CONCLUDING REMARKS}

From our work we suggest that insight can be gained by analyzing growth patterns of urbanized levels within an economy-wide framework that gives justice to circular flow. In this paper, results on urban performance were obtained from two social accounting matrices (SAMs) for The Netherlands, one for 1981 and one for 1985.

Admittedly, this short period cannot succeed in distinguishing long trends, but when our results are taken together with similar results obtained for the period 1978-81 in a comparable context [5], they do indicate some very likely trends in the medium term.

In our SAMs, we introduced households classified by degree of urbanization (rural municipalities, urbanized rural municipalities dormitary towns, small towns, medium-sized towns and large towns). The SAM is demonstrated to form an appropriate framework for integrating various statistical sources on regional development, and for studying the structural properties of 
the economy and intervening external forces in determining growth and distribution. It was shown empirically for the country and period concerned that the externally intervening forces gain in strength as compared to the internally structuring forces in determining the income growth of urbanization levels and the output growth of production sectors. It was shown further that large towns and the services sector are experiencing negative growth bias in terms of both internal and external influencing forces. Taking into account the working of the circular flow, the economic model employed here suggests that a deconcentration of cities towards towns, rural municipalities, dormitory towns and small towns goes simultaneously with enhanced growth for the sectors of mining, banking and public utilities at the cost of light industry, construction and services.

Acknowledgements-The author acknowledges with thanks the contribution of Drs J.M.C. Tuyl as co-author of a preliminary draft related to the paper cf., [9].

\section{REFERENCES}

1. I. Adelman, J.E. Taylor and S. Vogel. Life in a Mexican Village: a SAM perspective. J. Dev. Stud. 25, 5-24 (1988).

2. L. van den Berg. Urban Systems in a Dynamic Society. Gower Publishing, Aldershot (1987).

3. L. van den Berg and J. van der Meer. Dynamics of urban systems: general trends and Dutch experiences. Environ. Plann. 20, 1471-1486. (1988).

4. CBS. DBO Budgetresearch 1981/85: National and regional basic figures (in Dutch), Central Bureau of Statistics, The Hague, $(1981 ; 1985)$.

5. S.I. Cohen. A social accounting matrix analysis for the Netherlands. De Economist 2, 253-272 (1988).

6. S.I. Cohen. Analysis of social accounting multipliers over time: the case of the Netherlands. Socio-Econ. Plann. Sci. 23, 291-302 (1989).

7. S.I. Cohen. Multiplier analyses in social accounting and input-output frameworks: evidence for several countries. Frontiers of Input-Output Analysis (Edited by R.E Miller et al.). Oxford University Press (1989).

8. S.I. Cohen and J.M.C. Tuyl. Growth and equity effects of changing demographic structures in the Netherlands: simulations within a social accounting matrix. Econ. Modell. 8, 3-15 (1991).

9. S.I. Cohen and J.M.C. Tuyl. Recent urban growth and distribution in the Netherlands, SAM applications, Institute for Economic Research, Rotterdam, Discussion paper 9107/G (1991).

10. J.I. Round. Decomposition of input-output and economy-wide multipliers in a regional setting. Frontiers of Input-Output Analysis (Edited by R.E. Miller et al.), pp. 79-99. Oxford University Press (1989).

\section{APPPENDIX}

Table Al. The social accounting matrix of The Netherlands 1985 in millions of guilders

\begin{tabular}{|c|c|c|c|c|c|c|c|c|c|c|c|}
\hline Expen & $\begin{array}{c}\text { Products } \\
1\end{array}$ & $\begin{array}{c}\text { Wages } \\
2\end{array}$ & $\begin{array}{c}\text { Profits } \\
3\end{array}$ & $\begin{array}{c}\text { Household } \\
4\end{array}$ & $\begin{array}{c}\text { Firms } \\
5\end{array}$ & $\begin{array}{c}\text { Government } \\
6\end{array}$ & $\begin{array}{c}\text { Social } \\
\text { security } \\
7\end{array}$ & $\begin{array}{c}\text { Capital } \\
8\end{array}$ & $\begin{array}{c}\text { Activities } \\
9\end{array}$ & ROW & Total \\
\hline $\begin{array}{l}1 \\
2 \\
3\end{array}$ & & & & 247,720 & & 64,550 & 3120 & & $\begin{array}{l}216,762 \\
121,352\end{array}$ & $\begin{array}{r}80 \\
600\end{array}$ & $\begin{array}{l}315,390 \\
216,842 \\
121,952\end{array}$ \\
\hline $\begin{array}{l}4 \\
5\end{array}$ & & 166,092 & $\begin{array}{l}84,722 \\
33,610\end{array}$ & & & 31,810 & 82,230 & & & -1487 & $\begin{array}{r}363,367 \\
33,610\end{array}$ \\
\hline $\begin{array}{l}6 \\
7\end{array}$ & 19,124 & 50,750 & $\begin{array}{r}2870 \\
750\end{array}$ & $\begin{array}{l}42,420 \\
35,240\end{array}$ & & 2720 & & 6288 & 11,027 & $\begin{array}{l}-959 \\
-730\end{array}$ & $\begin{array}{l}93,830 \\
88,730\end{array}$ \\
\hline 8 & & & & 37,987 & 20,550 & -5250 & 3380 & & 42,867 & $-16,790$ & 82,744 \\
\hline 9 & 254,700 & & & & & & & 52,778 & 228,286 & 240,272 & 776,033 \\
\hline 10 & 41,568 & & & & & & & 23,678 & 155,740 & 24,522 & 245,508 \\
\hline Total & 315,390 & 216,842 & 121,952 & 363,367 & 33,610 & 93,830 & 88,730 & 82,744 & 776,034 & 245,508 & $2,338,007$ \\
\hline
\end{tabular}


Urban growth and circular flow

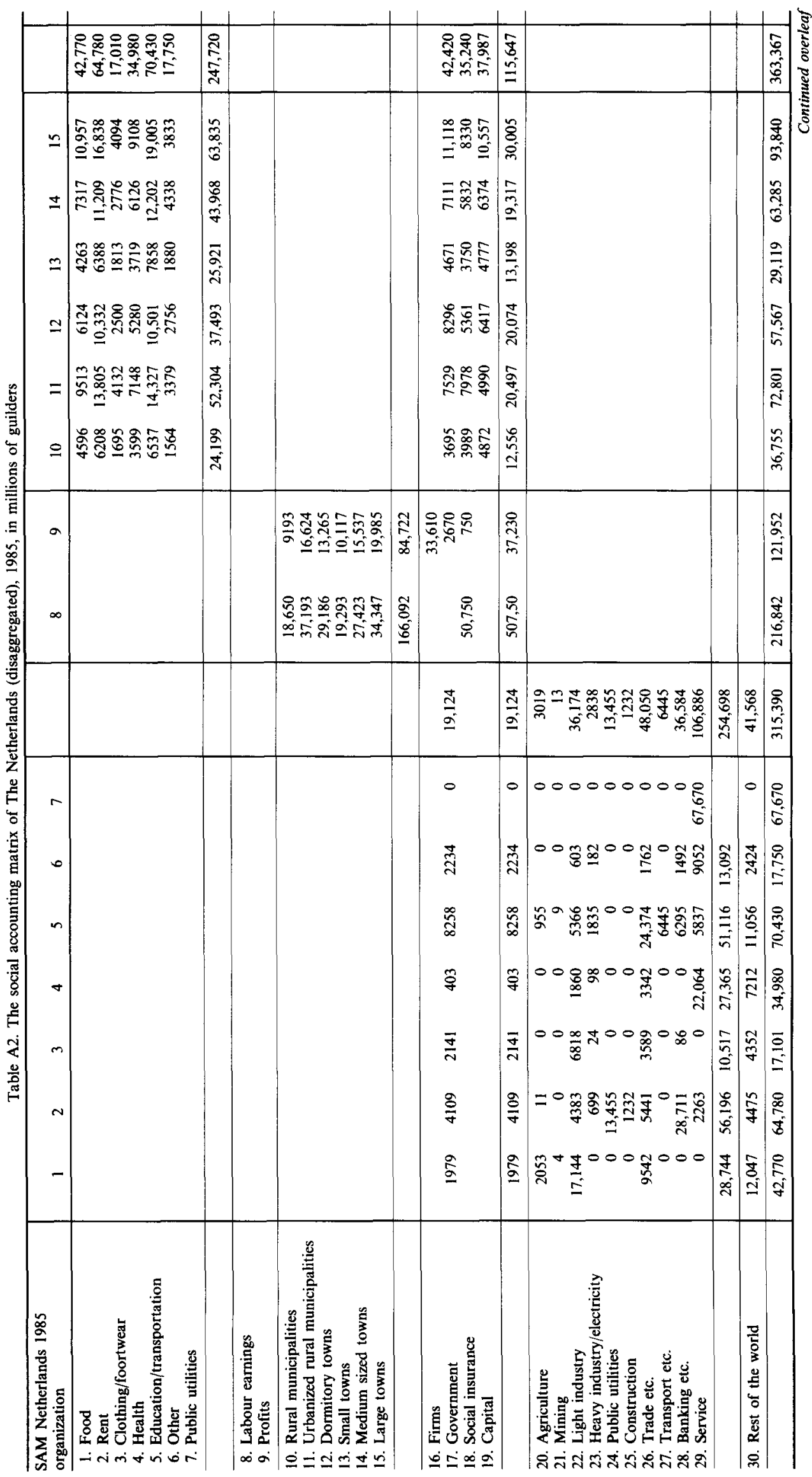




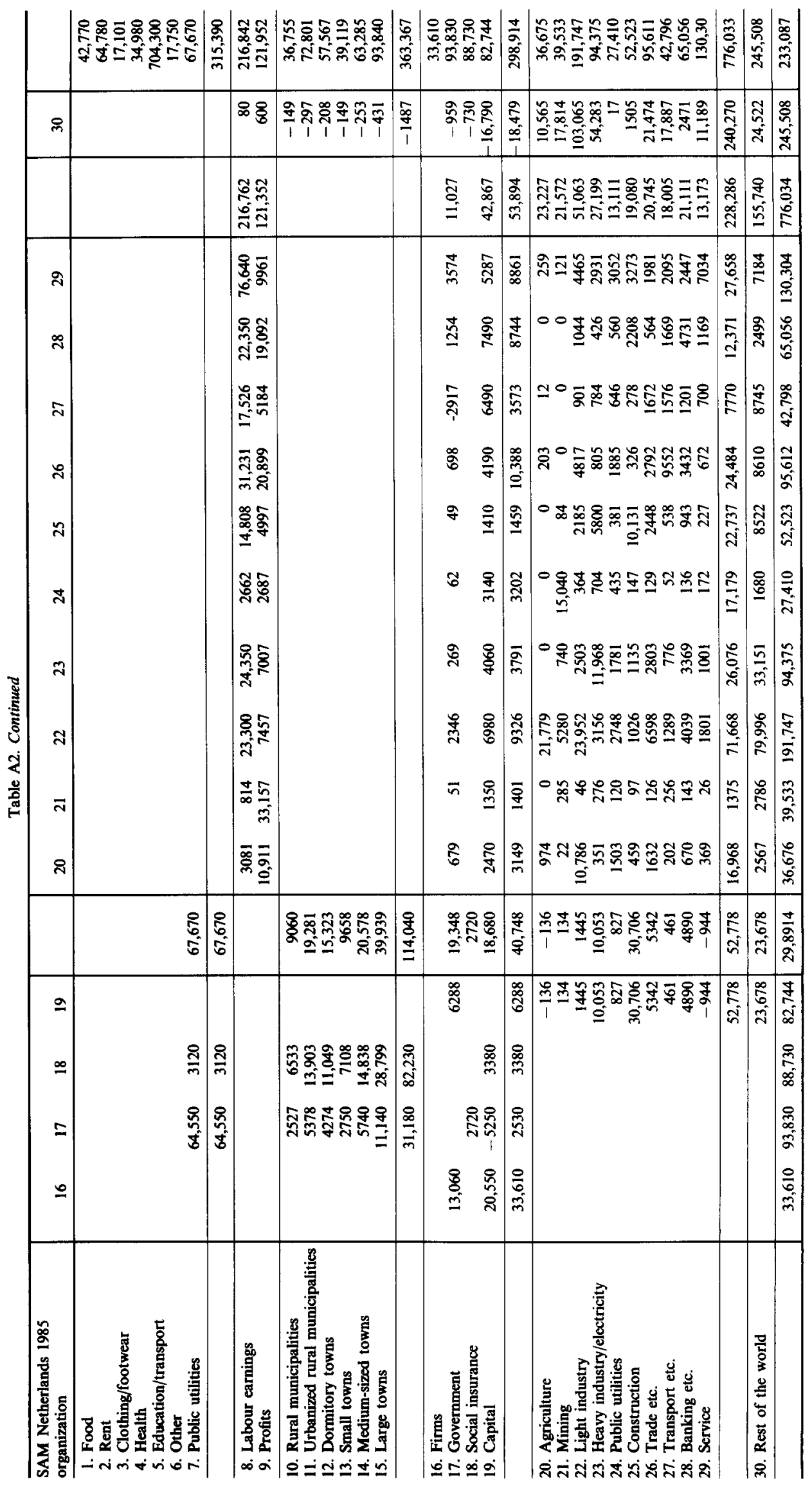

